\title{
ВНЕДРЕНИЕ ТЕХНОЛОГИЙ «БЕРЕЖЛИВОГО ПРОИЗВОДСТВА» В СФЕРУ ГОСУДАРСТВЕННОГО УПРАВЛЕНИЯ НА ПРИМЕРЕ ДЕЯТЕЛЬНОСТИ ОТДЕЛА РЕИНЖИНИРИНГА
}

\section{(C) 2021 Ситов Александр Николаевич}

кандидат экономических наук, доцент кафедры Технологии и организации перевозок Государственный университет морского и речного флота имени адмирала С. О. Макарова, Россия, Санкт-Петербург

E-mail: a.sitov@cipit.gov.spb.ru

\section{(c) 2021 Дудаков Георгий Сергеевич}

магистрант кафедры экономики исследований и разработок

Санкт-Петербургский государственный университет, Россия, Санкт-Петербург

E-mail: dudakov.gs@mail.ru

\section{(c) 2021 Севастьянов Николай Викторович}

ведущий специалист отдела реинжиниринга Управления развития инфраструктуры Комитета по промышленной политике, инновациям и торговле Санкт-Петербурга, Россия, Санкт-Петербург E-mail:n.sevastyanov@cipit.gov.spb.ru

\section{(c) 2021 Кириллов Михаил Алексеевич}

начальник отдела реинжиниринга Управления развития инфраструктуры Комитета по промышленной политике, инновациям и торговле Санкт-Петербурга, Россия, Санкт-Петербург E-mail:m.kirillov@cipit.gov.spb.ru

В статье рассмотрен опыт внедрения технологий «бережливого производства» в Комитете по промышленной политике, инновациям и торговле Санкт-Петербурга. Отмечены ключевые результаты внедрения данных технологий в Комитете и его подведомственных учреждениях, за которые ответственно специально созданное структурное подразделение - отдел реинжиниринга Управления развития инфраструктуры Комитета. В статье также рассмотрены теоретические основы процессного управления и бизнес-процессов, определены характеристики и функции процессов.

Ключевые слова: процессное управление, бизнес-процессы, бережливое производство, эффективность, современные технологии, эффективный регион.

Деятельность Комитета по промышленной политике, инновациям и торговле СанктПетербурга (далее - Комитет) направлена на разработку и реализацию государственной политики Санкт-Петербурга в сферах промышленности, инноваций и потребительского рынка, на координацию деятельности исполнительных органов государственной власти Санкт-Петербурга в сфере развития промышленности и инновационной деятельности, агропромышленного комплекса, развития предпринимательской деятельности, в том числе, среднего и малого бизнеса, потребительского рынка, а также на проведение государственной политики СанктПетербурга в сфере лицензирования отдельных видов деятельности, обеспечения продовольственной безопасности Санкт-Петербурга и государственного регулирования в данной сфере.
В настоящее время Комитет проводит системную работу по внедрению в государственное управление современных технологий, подходов и принципов управления, способствующих снижению неэффективных расходов, созданию удобных сервисов для бизнеса и повышению качества жизни граждан, ключевыми из которых являются:

1. Процессное управление и оптимизация процессов;

2. Применение цифровых технологий в государственном управлении.

Процессное управление и оптимизация процессов

Процессное управление - это современная концепция управления, которая рассматривает деятельность любой организации как совокупность бизнес-процессов и предоставляет набор 
механизмов и инструментов для их оптимизации.

Медведев Л.Ф. отмечает, что «процессный подход дает возможность выделить такую категорию, как бизнес-процесс. Бизнес-процесс, как правило, начинается с анализа спроса потребителей и заканчивается удовлетворением выявленного спроса». В данном случае речь идет о контакте и взаимодействии внутренней и внешней среды организации. Подобное взаимодействие описывается посредством бизнеспроцессов [7]. При рассмотрении процессного подхода и бизнес-процессов крайне важным является определений ключевых функций и характеристик процессов, поскольку это позволяет более детально разобраться в их функционировании (см. табл. 1).

По мнению М.О.Дорошенко «Процессный подход к управлению, по мнению российских специалистов в области менеджмента, имеет ряд преимуществ:

- гибкость системы управления;

- высокая мотивация сотрудников;

- прозрачность организационной структуры и бизнеса в целом;

- ориентация на максимальное удовлетворение потребностей клиентов» [6].

Внедрение процессного управления является одной из ключевых задач Комитета в сфере повышения эффективности государственного управления. В связи с этим, Комитет в 2020 году одним из первых исполнительных органов государственной власти Санкт-Петербурга включился в реализацию совместной программы субъектов РФ и ГК «Росатом» «Эффективный регион».

В рамках реализации данной программы в целях проведения оптимизации существующих процессов в Комитете создано отдельное структурное подразделение - отдел реинжиниринга Управления развития инфраструктуры Комитета (далее - отдел реинжиниринга), целью которого является внедрение технологий «бережливого производства» в государственном управлении с учетом опыта специалистов $\mathrm{AO} \ll \Pi С$ « (ГК «Росатом»).

Согласно КлочковуЮ.П. «ключевая цель концепции «бережливого производства» - избавиться от потерь, не создающих ценность операций в процессе оказания услуг или производстве» [5].

На рис. 1 рассмотрены методы «бережливого производства».

Проведя анализ деятельности Комитета сотрудниками отдела реинжиниринга выявлено 332 процесса, которые условно разделены на 4 группы по основным направлениям деятельности Комитета. Из них выделено 92 ключевых процесса, оказывающих непосредственное влияние на формирование комфортной среды для ведения бизнеса, что способствует достижению показателей национальных целей развития Российской Федерации на период до 2030 года, определенных Указом Президента Российской Федерации от 21.07.2020 № 474, и индикаторов, утвержденных Указом Президента Российской Федерации от 04.02.2021 № 68 [1-2].

В рамках сотрудничества между Правительством Санкт-Петербурга и ГК «Росатом» в 20202021 годах при участии специалистов АО «ПСР» реализовано шесть проектов по оптимизации процессов и внедрению «бережливых технологий»:

1. Оптимизация процесса выдачи лицензии на розничную продажу алкогольной продукции.

Таблица 1. Характеристики и функции процесса [4]

\begin{tabular}{|l|l|}
\hline \multicolumn{1}{|c|}{ Процесс } & \multicolumn{1}{|c|}{ Фунция } \\
\hline $\begin{array}{l}\text { Предсказуемость. Низкий уровень } \\
\text { неопределенности }\end{array}$ & $\begin{array}{l}\text { Гибкость. Быстрая реакция на } \\
\text { возникающие ситуации }\end{array}$ \\
\hline Координация на основе стандартов & $\begin{array}{l}\text { Координация на основе оперативных управленче- } \\
\text { ских решений }\end{array}$ \\
\hline Гарантированный результат & $\begin{array}{l}\text { Высокий уровень неопределенности } \\
\text { качества результата }\end{array}$ \\
\hline Прозрачность & $\begin{array}{l}\text { Управление на основе неполной } \\
\text { информации }\end{array}$ \\
\hline $\begin{array}{l}\text { Управление потерями на основе } \\
\text { статистических методов }\end{array}$ & Высокий уровень потерь \\
\hline Низкие затраты на управление & Высокие затраты на управление \\
\hline
\end{tabular}




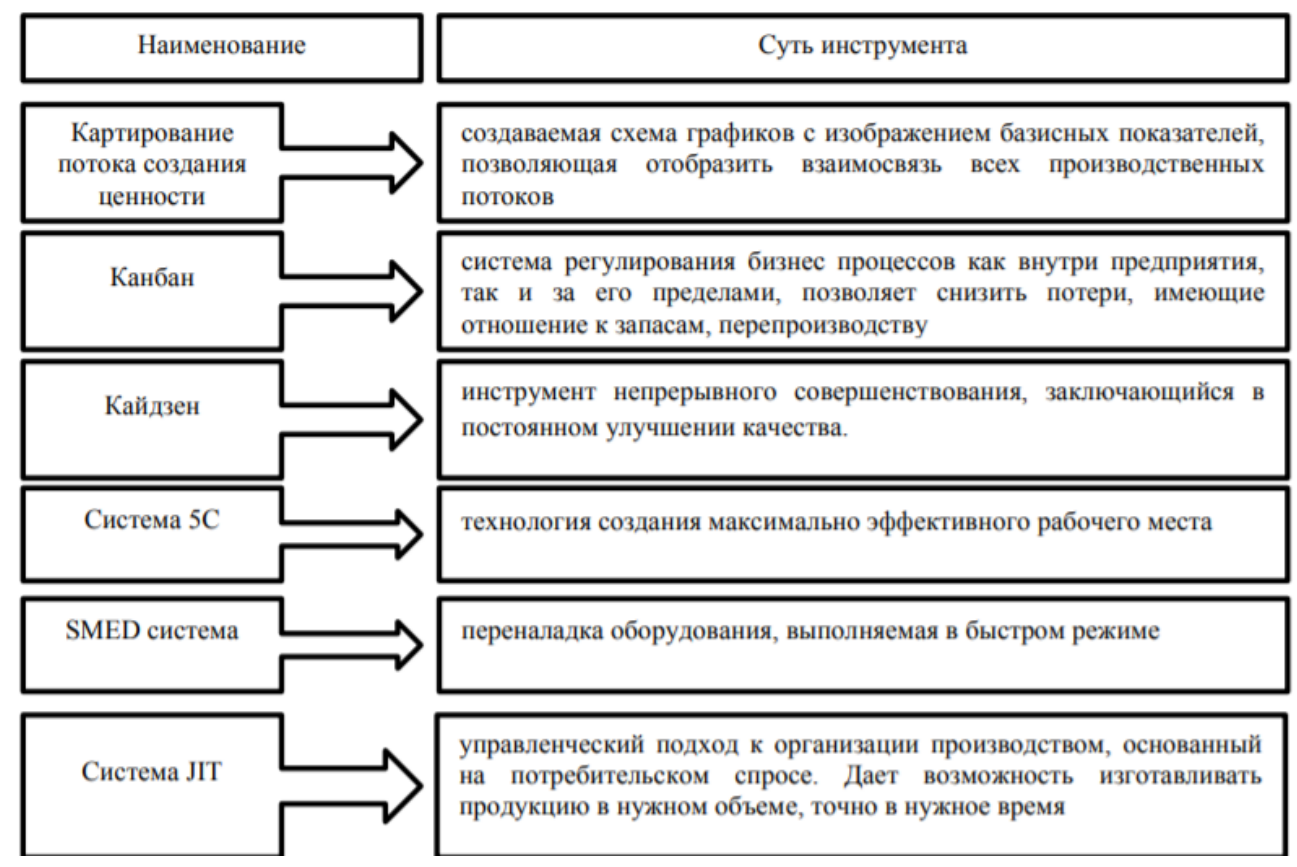

Рuc. 1. Методы «бережливого производства» [3]

В рамках проекта были реализованы следующие мероприятия:

- внедрена система контроля документооборота;

- совместно с Комитетом по информатизации и связи доработана АИС-лицензирование;

- сокращено количество подписантов и дублирующих проверок.

В результате реализации проекта срок выдачи лицензий на розничную продажу алкогольной продукции сокращен с 42 до 26 дней.

2. Оптимизация процесса разработки и утверждения схемы размещения нестационарных торговых объектов.

В рамках проекта были реализованы следующие мероприятия:

- сокращены цепочки согласующих лиц в процессе формирования заявления на включение в схему размещения нестационарных; торговых объектов (далее - НТО), а также сроки подготовки итогового заключения Комитетом имущественных отношений;

- проведена работа по корректировке сведений об объектах, содержащихся в схеме НТО, с целью дальнейшей актуализации сведений в РГИС.

В результате реализации проекта срок разработки и утверждения схемы размещения НТО сокращен с 40 до 14 дней.

3. Повышение эффективности соблюдения стандартов безопасной деятельности организа- циями и индивидуальными предпринимателями в период пандемии новой коронавирусной инфекции.

В рамках проекта были реализованы следующие мероприятия:

- разработаны стандартный акт осмотра, форма отчетности, памятки для предпринимателей по получению QR-кодов, а также чек-лист самопроверки;

- организован сбор ежедневной отчетности по обходам и ее сведение в единый реестр для мониторинга общей ситуации по городу;

- на сайте СПб ГБУ «Центр развития и поддержки предпринимательства» (далее - ЦРПП) внедрена интерактивная карта организаций.

В результате реализации проекта срок получения организациями QR-кода и обработки обращений граждан с проведением контрольнонадзорных мероприятий сокращен с 15 до 7 дней.

4. Оптимизация процесса рассмотрения поступивших заявок на предоставление займов, подготовки и согласования необходимых документов для выдачи займов НКО «Фонд развития промышленности Санкт-Петербурга» (далее Фонд).

В рамках проекта были реализованы следующие мероприятия:

- разработаны регламенты деятельности экспертного и наблюдательного советов Фонда;

- актуализированы разделы в «личном ка- 
бинете» на сайте Фонда;

- сформирован электронный буклет с описанием программ заимствования.

В результате реализации проекта средний срок рассмотрения заявок на выдачу займов сокращен с 92 до 44 дней.

5. Внедрение процессного подхода в АО «Технопарк Санкт-Петербурга» (далее Технопарк).

В рамках проекта были реализованы следующие мероприятия:

- сформирован прайс-лист по 70\% услуг Технопарка;

- проведена цифровизация процесса заключения договоров на оказание услуг;

- разработаны формы типовых договоров на оказание услуг.

В результате реализации проекта количество услуг, оказанных Технопарком субъектам малого и среднего предпринимательства (далее - МСП) за 9 месяцев 2021 года, увеличилась в 2,5 раза по сравнению с аналогичным периодом «доковидного» 2019 года.

6. Оптимизация процесса предоставления субсидий субъектам предпринимательской деятельности Санкт-Петербурга.

В рамках проекта были реализованы следующие мероприятия:

- разработан интерфейс портала ЦРПП для предоставления субсидий;

- разработан регламент работы пользователя в информационной системе;

- сформированы типовые формы документов.

В результате реализации проекта среднее время предоставления субсидий будет сокращено с 51 до 23 дней.

В целях повышения эффективности региональной инфраструктуры поддержки субъектов МСП и исключения дублирования функций 18.01.2021 в Комитете сформирована Комиссия по повышению эффективности региональной инфраструктуры поддержки субъектов МСП в Санкт-Петербурге.

По итогам деятельности в первом полугодии 2021 года Комиссией сформирован Перечень услуг организаций, образующих инфраструктуру поддержки субъектов МСП в Санкт-Петербурге (далее - Перечень), позволивший исключить дублирование услуг, предоставляемых субъектам МСП и оптимизировать расходование средств городского бюджета. В настоящее время Комис- сией на постоянной основе ведется работа по актуализации Перечня и мониторингу востребованности предоставляемых услуг.

В целях дальнейшего внедрения процессного подхода и оптимизации действующих процессов Комитетом на период до 2024 года запланирована работа по оптимизации $100 \%$ основных процессов и $70 \%$ вспомогательных.

Комитет проводит системную работу по цифровой трансформации государственного управления в сфере промышленности.

В рамках реализации Стратегии в области цифровой трансформации отраслей экономики, социальной сферы и государственного управления Санкт-Петербурга 22.09.2021 утвержден план мероприятий цифровой трансформации Комитета на период 2021-2022 годы, основными мероприятиями которого являются:

1. Внедрение системы поощрения постоянных улучшений в деятельности Комитета и подведомственных организаций. В результате реализации данного мероприятия количество внедренных улучшений в деятельность Комитета увеличится не менее, чем в 2 раза.

2. Проведение обучения не менее $50 \%$ работников Комитета основам цифровой трансформации. По состоянию на 14.12.2021 года обучение прошли 69 работников Комитета (78\% из планируемых к обучению в 2021 году).

3. Разработка и внедрение с учетом принципа клиентоориентированности информационных систем, цифровых сервисов и цифровых платформ для взаимодействия с гражданами, организациями, федеральными органами исполнительной власти и институтами развития:

- в рамках программы «Эффективный регион» Комитетом проводится цифровизация сервисов на потребительском рынке СанктПетербурга. Целью данного проекта является создание электронных сервисов, с помощью которых будет осуществляться подача и отслеживание заявлений на лабораторные исследования потребительской продукции, а также предоставление торговых мест на рынках и ярмарках Санкт-Петербурга. Внедрение электронных сервисов позволит не менее чем в 2 раза сократить время осуществления процессов;

- внедрение CRM-системы для единого учета данных оказанных мер поддержки субъектам МСП. На данный момент в части функционала CRM-системы реализована возможность обработки заявок на получение услуг от юридических 
и физических лиц, применяющих специальный налоговый режим «Налог на профессиональный доход». В рамках взаимодействия с АО «Корпорация МСП» ведется работа по технической интеграции CRM-системы, маркетплейса услуг МСП и платформы АО «Корпорации МСП». По состоянию на 10.11.2021 в СRМ-систему внесено 7,8 тыс. услуг;

- для обеспечения ускоренного восстановления и развития МСП в постковидный период на платформе ЦРПП запущен Городской акселератор - это цифровая платформа для МСП, в рамках которой бизнес может получать различные виды персонализированной поддержки. Городской акселератор реализуется по таким направлениям, как: сфера услуг (в том числе рестораны, кафе, бытовые услуги населению), производство и технологии, креативные индустрии, социальное предпринимательство. По состоянию на 09.11.2021 для участия в Городском акселераторе подано 8,9 тыс. заявок;

- в настоящее время прорабатывается вопрос разработки информационной системы промышленности Санкт-Петербурга как регионального сегмента ГИСП РФ. Санкт-Петербург выбран Минпромторгом России в качестве пилотного региона по разработке и внедрению регионального сегмента ГИСП РФ;

- в период распространения новой коронавирусной инфекции Правительством СанктПетербурга апробирован ряд комплексных решений и практик, одним из которых является внедрение на портале ЦРПП цифрового сервиса по присвоению QR-кода, подтверждающего согласие организации на соблюдение стандартов безопасной деятельности. Введение QR-кода позволило структурировать работу организаций и индивидуальных предпринимателей, направленную на осуществление (возобновление) деятельности в период пандемии. По состоянию на 10.11.2021 года организациям Санкт-Петербурга выдано более 138 тыс. QR-кодов;

- в части цифровизации контрольнонадзорной деятельности Комитетом совместно с Прокуратурой Санкт-Петербурга на портале ЦРПП реализован пилотный цифровой проект «Самообследование», направленный на оптимизацию взаимодействия предпринимателей и органов государственной власти. Первым участником проекта стал Комитет по труду и занятости населения Санкт-Петербурга, который по заявке двух организаций, успешно прошед- ших процедуру «Самообследования», в рамках регионального государственного контроля (надзора) за приемом на работу инвалидов в пределах установленной квоты, снизил в отношении них количество контрольных мероприятий. В ближайшей перспективе сервис станет доступен для более чем десяти видов регионального государственного контроля, осуществляемых на территории Санкт-Петербурга. План развития проекта также предполагает консультирование предпринимателей по вопросам контрольнонадзорной деятельности и интеграцию с федеральными системами;

- в июле 2021 года Комитетом запущен Единый портал системообразующих организаций Санкт-Петербурга, с помощью которого через «личный кабинет» организована работа с системообразующими предприятиями СанктПетербурга. На данном портале внедрена система цифрового «консьерж-сервиса», которая позволяет оказывать персональную поддержку системообразующим промышленным предприятиям, в том числе при взаимодействии с федеральными и региональными органами государственной власти, государственными корпорациями, а также кредитными организациями и институтами развития;

- в целях повышения эффективности правового и информационного обеспечения жителей Санкт-Петербурга в сфере защиты прав потребителей реализован проект по созданию Информационного портала по защите прав потребителей (далее - Портал), который представляет собой единую цифровую платформу для взаимодействия потребителей товаров и услуг, государственных органов, внутригородских муниципальных образований и общественных объединений потребителей (некоммерческих организаций). Среди наиболее востребованных цифровых сервисов Портала такие, как: составление претензий при помощи конструкторапомощника и проверка товара на предмет отнесения его к технически сложным товарам. Портал позволяет объединить всех участников национальной системы защиты прав потребителей в Санкт-Петербурге, а также повысить прозрачность, оперативность и эффективность взаимодействия с жителями города в сфере защиты прав потребителей, повысить уровень их правовой и финансовой грамотности. Дальнейшее развитие Портала позволит в интерактивном режиме упростить и ускорить процесс 
оказания консультаций потребителям, оптимизировать затраты на содержание многочисленных «горячих линий», а также увеличить доступность бесплатных сервисов для жителей Санкт-Петербурга;

- через портал «Государственные и муниципальные услуги (функции) в Санкт-Петербурге» возможна подача заявления в электронном виде о выдаче, переоформлении разрешений на право организации розничных рынков на территории Санкт-Петербурга и продлении срока действия разрешений на право организации розничных рынков на территории Санкт-Петербурга;
Комплексное и системное применение в работе Комитета современных клиентоориентированных технологий управления, включая цифровые технологии, способствует снижению неэффективных расходов и повышению качества жизни граждан, формирует комфортную деловую среду для ведения бизнеса, в том числе для субъектов МСП, а также способствует реализации национальных проектов на территории Санкт-Петербурга. Таким образом, именно оптимизация в совокупности с цифровизацией позволила достичь рассмотренных в статье целей и задач.

\section{Библиографический список}

1. Указ Президента РФ от 21 июля 2020 г. № 474 «О национальных целях развития Российской Федерации на период до 2030 года» // Сайт Президента России [Электронный ресурc]. URL: http://www.kremlin.ru/acts/ bank/45726 (дата обращения: 14.11.2021).

2. Указ Президента РФ от 4 января 2021 г. № 68 «Об оценке эффективности деятельности высших должностных лиц (руководителей высших исполнительных органов государственной власти) субъектов Российской Федерации и деятельности органов исполнительной власти субъектов Российской Федерации» // Сайт Президента России [Электронный ресурс]. URL: http://www.kremlin.ru/acts/bank/46402 (дата обращения: 14.11.2021).

3. Вумек Дж. Бережливое производство: Как избавиться от потерь и добиться процветания вашей компании: учебное пособие/ Джеймс Вумек Дэниел Джонс; пер. с анг. - 7 - е изд. - М.: Альпина Паблишер, 2013. 472 c.

4. Зенина Н.Н. Координация в системе процессного управления / Н.Н. Зенина // Повышение производительности труда на транспорте - источник развития и конкурентоспособности национальной экономики: Труды V Всероссийской научно-практической конференции, Москва, 26 мая 2021 года. - Москва: Гуманитарный институт федерального государственного бюджетного образовательного учреждения высшего образования «Российский университет транспорта (МИИТ)», 2021. - С. 102-106.

5. Клочков Ю.П.Бережливое производство: понятия, принципы, механизмы // Инженерный вестник Дона. 2012. Т. 20, № 2. С. 429-437.

6. Круликовский А.П. Анализ проблем внедрения процессного подхода к управлению / А.П. Круликовский, А. О.Декалюк // Тенденции развития интернет и цифровой экономики: Труды III Всероссийской с международным участием научно-практической конференции, Симферополь- Алушта, 04-06 июня 2020 года. Симферополь- Алушта: ИП Зуева Т. В., 2020. - С. 279-280.

7. Медведева Л.Ф. Современный инструментарий процессного управления / Л.Ф. Медведева // Актуальные проблемы науки и техники. Инноватика: Сборник статей по материалам международной научнопрактической конференции, Уфа, 14 января 2020 года. - Уфа: Общество с ограниченной ответственностью «Научно-издательский центр «Вестник науки», 2020. - С. 170-175. 